\title{
Effect of Environment and Technology on Child on Child Sexual Abuse in Indonesia
}

\author{
A Sofian' ${ }^{1}$ I Hermawati², E Winarno ${ }^{3}$ \\ ${ }^{1}$ Faculty of Humanities, Universitas Bina Nusantara, Jakarta, Indonesia \\ ${ }^{2,3}$ Researchers at Research Institute and Social Welfare Service Development of the Ministry \\ of Social Affairs of the Republic of Indonesia
}

1asofian@binus.edu

\begin{abstract}
The research aimed to identify the characteristics of child sexual abuse, its contributing factors, and active social intervention. Both quantitative and qualitative methods were applied in the research. The research involved the questionnaires, conducted in-depth interviews and also organized focused group discussions in the five cities. The research uncovered that child on child sexual abuse was perceived not only as normal sex but also as a sexual assault by children to other children. There were some factors that significantly contributed to this such as childhood exposure to pornography, the influence of peers, the lack of the campaign for safe internet access as well as the lack of parents' and teachers' knowledge to protect children from the negative effects of the internet. Therefore, it was recommended to develop formal and informal education models to reduce children's time accessing pornographic and harmful websites which did not support their capacity and character building, develop offline or gadget-based games and make a policy on multi-system therapy, an intensive therapy system which targets not only child sex offenders but also their peers, parents, teachers (schools), neighbors and communities. Moreover, it was also recommended to improve the coordination between law enforcement agencies and rehabilitation centers.
\end{abstract}

Keywords: Sexual, Children, Pornographic

\section{INTRODUCTION}

The phenomena of child sexual abuse have raised serious concerns. Data from the Central Bureau of Statistics exhibit that there were 247,610 children who were the victims of the abuse in 2014. It was estimated that 74,283 of them were the victims of sexual abuse. Meanwhile, data from the Commission for the Protection of Indonesian Children indicates that about $30 \%$ or about 1,965 cases of the total child abuse cases from 2011 to 2016 were child sexual abuse cases. Interestingly, the number of children who are sex offenders and victims is almost identical every year. For more details, please refer to Chart 1 below.

On the other side, globalization and easy access to information engender negative effects on children. They can easily access information without proper supervision and filter while 
families, as the main protector, fail to protect them. Although the Government of Indonesia has made various policies to protect children from abuse, the fundamental rights of children who aresex offendersand victims have not yet been fulfilled. Additionally, law enforcers are not yet sensitive to them [1]. Phenomena of children who sexually abuse other children exist not only in Indonesia but also in other countries in the world. Unfortunately, there are only very limited studies to find out why children sexually abuse other children. Even, there is no such study in Indonesia.

\section{METHOD}

A mixed method of quantitative and qualitative methods was applied in this research. The tools of data collection in the researchare the questionnaire and interview guideline. Questionnaires comprised of questions on the frequency of violence committed including the socioeconomic conditions. On the other hand, the interview guide contained questions regarding the motivation for attemptingthe violent act, its own factors, and impacts. These two research methods were treated equally and complement each other [2].Two approaches were used in the research, namely: victimology and social approaches because there were some factors such as exposure to pornography, peer influence, and family situations. Victimology is a branch of science to study human or belonging victimization as a social fact. It would help the researchers identify problems faced by victims of sexual abuse who became sex offenders $[2]$.

The population in this study involved children who had committed acts of sexual violence against other children and recorded as beneficiaries in the institutions (PSMP, RPSA) and non-institutions (LPA and LPKA) in the last one year. The sampling of the research, total sampling, is a quantitative-based method. It congregates the entire population that complies with the criteria as the sample. Informants are determined through the technique of snowball sampling for qualitative methods. Based on the results, 157 research subjects were involved in the study, consisting of 49 male respondents (perpetrators of sexual violence), 59 informants who include 20 male and 39 female, and 48 FGD participants of 20 male and 28 female.

The data populated in this study is quantitative and analyzed with descriptive statistics. Meanwhile, the qualitative data were analyzed by using the descriptive interpretative technique [3].

\section{RESULT and DISCUSSION}

Howard E. Barbaree and William L. Marshall divide offenders of a child on child sexual abuse into two categories: children and juveniles. Children cannot be held criminally responsible for sexual abuse. In many countries, someone under 12 years is categorized as a child. In other words, children under 12 years cannot be categorized as a sex offender and they, therefore, cannot be held criminally responsible for a criminal offence. Meanwhile, juveniles are children who commit a crime but they can be held criminally responsible for a criminal offence. Generally, they range from 12 to 17 years old. Therefore, if children who fall into these age groups commit a sexual offence, they can be held criminally responsible for the offence. In the USA, they are called juvenile sex offender. More specifically, juvenile sex offender is defined as a person who has been convicted of a sexual offense and who is considered by law to be old enough to be held criminally responsible for the crime (generally by age enough), but not so old as to be full range of adult criminal sanction (as would be the case after his or her $18^{\text {th }}$ birthday) [4]. According toJohn A. Hunter, there are four factors of 
child sexual abuse: 1) Past sexual abuse; 2) Exposure to pornography; 3) Influence of peers and; 4) Family environment [5].

Characteristics of family social/economic: Most of the respondents $(56.26 \%)$ were from intact families. $62.5 \%$ of respondents from Magelang were from intact families; $60 \%$ of respondents from Jakarta and Yogyakarta were from intact families; $57.1 \%$ of respondents from Mataram were from intact families, and $41.7 \%$ of respondents from Makassar were from intact families. $50 \%$ of the respondents said that one of or both parents had died. Most of their fathers were elementary school graduates and only a small number of them was senior high school graduates. Meanwhile, most of their mothers were senior high school graduates and a small number of them were junior high school graduates. $46 \%$ of their fathers and $48.9 \%$ of their mothers worked in informal sectors and had low incomes. This showed that most of the respondents' families came from lower social status.

Characteristics of offenders: $100 \%$ of the child sex offenders were boys between the ages of 11 and 18 years old. So, the average age of the offenders was 16 years. $61.2 \%$ of them lived with their parents when they sexually abused other children. $30.56 \%$ of them said that they sexually abused other children at their friends' house and $19.44 \%$ of them said that they sexually abused other children in their victims' house. $30 \%$ of them said that they only touched or rubbed victims' genitals and $26 \%$ of them said that they had sex with the victims. $67 \%$ of the child sex offenders said that they used coercion when they sexually abused the victims. The research also found that one of the child sex offenders had sexually abused 20 children.

Characteristics of victims: There were a total of 74 victims and 22 of them $(30 \%)$ were boys. $87 \%$ of the victims knew the offenders and $69 \%$ of them had known the offenders for a long time (between 1 and 3 years). The victims were between 5 and 17 years old. According to the offenders, $35.44 \%$ of the victims were silent, shy or tearful children; 24.05 of them were hyperactive and naughty children, and $13.92 \%$ of them often wore sexy clothes.

Table 1. Data on sexual abuse cases handled by four rehabilitation centers of the Ministry of Social Affairs of the Republic of Indonesia and Child Protection Institution of Yogyakarta from 2014 to 2017.

\begin{tabular}{|c|c|c|c|c|c|c|c|c|c|c|c|c|c|}
\hline \multirow{3}{*}{ No } & \multirow{3}{*}{ Year } & \multicolumn{12}{|c|}{ Location } \\
\hline & & \multicolumn{2}{|c|}{ Jakarta } & \multicolumn{2}{|c|}{ Magelang } & \multicolumn{2}{|c|}{ Mataram } & \multicolumn{2}{|c|}{ Makassar } & \multicolumn{2}{|c|}{ Yogyakarta } & \multicolumn{2}{|c|}{ Total } \\
\hline & & $\mathrm{M}$ & $\mathrm{F}$ & $\mathrm{M}$ & $\mathrm{F}$ & $\mathrm{M}$ & $\mathrm{F}$ & $\mathrm{M}$ & $\mathrm{F}$ & $\mathrm{M}$ & $\mathrm{F}$ & $\mathrm{M}$ & $\mathrm{F}$ \\
\hline 1 & 2014 & - & - & 9 & - & 3 & - & - & - & 25 & 1 & 37 & 1 \\
\hline 2 & 2015 & 25 & - & 30 & - & 22 & - & 10 & - & 7 & - & 94 & - \\
\hline 3 & 2016 & 40 & - & 21 & - & 14 & - & 4 & - & 3 & - & 82 & - \\
\hline 4 & 2017 & - & - & 12 & - & 15 & - & - & - & 1 & - & 28 & - \\
\hline & Total & 65 & - & 72 & - & 54 & - & 14 & - & 36 & 1 & 241 & 1 \\
\hline
\end{tabular}

There were four determinant factors of a child on child sexual abuse. The first factor was exposure to pornography (43\%). This was facilitated by mobile phone $(28 \%)$, computer $(24 \%)$, images/photos (18\%) and CD/VCD (12\%). The second factor was the influence of peers. Sexual abuse by peers took different forms such as showing pornographic images/photos (42\%), touching or rubbing children's genitals (17\%) and having sex with children $(16 \%)$. The third factor was past sexual abuse. $22 \%$ of the respondents said that they had been sexually abused in which someone showed them pornographic images/films (57\%) and forced them to 
do a sexual activity and have sex $(28 \%)$. The fourth factor was exposure to sexual activities at home by family members. They also did not get any protection from their families when they accessed pornographic contents on the internet. Another factor that encouraged children to sexually abuse other children was drug abuse and alcohol (11\%).

The data of qualitative research is used to analyze the cases of violence that impact on children.This study has implications for efforts to overcome child sexual violence by children. Cases of sexual violence are usually committed by adults to children over the years [6]. However, with the rampant cases of sexual violence perpetrated by children, it indicates the requirement for a new policy in formulating the steps in handling the problem. Policies for the prevention of child sexual violence by children are not only embodied with preventive measures, but also the steps to rehabilitate the perpetrators and victims so that special interventions, particular modules, and specialized trained staff in tackling the problem [7].

The limited literature and previous research that addressed this issue became the greatest impediment encountered by researchers. Researchers also experience challenges when it comes to developing research instruments aimed at children. Researchers decided on the use of a questionnaire to capture quantitative information from children who have sexually abused The researchers believe that questionnaires sometimes function improperly as means of interviewing children. As interviewing children, the use of questionnaires becomes so rigid as the questionnaire used should be able to acquire as much information as possible from the child but not in depth. In fact, considerable interesting stories require being analyzed. In this context, the researchers prepared questionnaires with closed and open questions for balanced information. In the operational purview, researchers often encounter informants who lack information related to the issues that induce not optimum results in this study.

The study reveals that the handling of child sex offenders against children in the context of law enforcement holds the same nature. Law enforcers are susceptible to equate the handling of all perpetrators even though the motives of children perpetrating sexual violence vary [8]. Therefore, the context of the handling of perpetrators of sexual violence should be distinguished by the perpetrators by paying attention to the motives and factors that induce children to engage in sexual violence [9]. Howard E. Barbaree and William L. Marshall articulated the difference in the handling of child sex offenders who have abusive elements and vice versa should be differentiated. Likewise, the difference in handling by law enforcement between perpetrators of sexual violence who do so with likes and who have abusive elements should be distinguished. The study denotes that $33 \%$ of child sex offenders who do so on a mutual basis implies no coercion, persuasion, or pressure/intimidation.

\section{CONCLUSIONS}

It is recommended to develop and implement a National Plan of Action for the Elimination of Child Sexual Abuse with a focus on prevention efforts through a family and communitybased child protection and offender recovery through a multi-system therapy. It is also important to map child sexual abuse to collect comprehensive data to assess the prevalence of intervention programs. This must involve relevant ministries and institutions such as the Ministry of Social Affairs, the Ministry of Women's Empowerment and Child Protection, the Ministry of Health, the Ministry of Religious Affairs and the Ministry of Education.

The Ministry of Communication and Information needs to make a policy or regulation on the sale of special smartphones to children to prevent them from accessing pornographic contents. This policy must involve private sectors and state-owned companies which provide mobile phone and network tools. Children who commit sexual abuse must be treated 
differently from children who commit other abuse. Therefore, the Ministry of Social Affairs needs to develop a module about this and it must be followed by capacity building and synergy between law enforcers and social workers. The Ministry of Justice and Human Rights have to harmonize national laws and international instruments which have been ratified by the Government of Indonesia, especially the Optional Protocol to the Convention on the Rights of the Child on the Sale of Children, Child Prostitution and Child Pornography, to enable us to address sex offenders, rehabilitate victims and prevent child sexual abuse.

\section{REFERENCES}

[1] A. Sofian, G. Krisna, and A. Ardian, Global Study on Sexual Exploitation of Children in Travel and Tourism (Country Specific Report Indonesia). Jakarta: ECPAT Indonesia, 2016.

[2] L. E. Cohen and M. Felson, "Social Change and Crime Rate Trends: A Routine Activity Approach," Am. Sociol. Rev., vol. 44, no. 4, p. 588, Aug. 1979.

[3] Finklhor, Child Sexual Abuse: New Theory and Research. New York: Free Press, 1984.

[4] C. Beaulieu, Strengthening Laws Addressing Child Sexual Exploitation: A Practical Guide. Bangkok: ECPAT Internationa, 2008.

[5] J. A. Hunter, Understanding Juvenile Sex Offender:Research Findings and Guidelines for Effective Management and Treatment. Virginia: Institute of Law, Psychiatry and Public Policy, University of Virginia, 1995.

[6] H. E. Barbaree and W. L. Marshall, An Introduction to the Juvenile Sex Offender" in The Juvenile Sex Offender 2016. New York: The Guildford Press, 2016.

[7] Sidabutar, Community-based Psychosocial Recovery. Jakarta: Kontra S \& Yayasan PULIH, 2003.

[8] JKG Group, Stop it now. Do Children Sexually Abuse Other Children? Preventing sexual abuse among children and youth. Northampton: JKG Group, 2007.

[9] B. Widyastuti, An Analysis of Determinant Factors of Boys Committing Sexual Abuse, Thesis, Criminology Study Program. Depok: Faculty of Social and Political Sciences, Universitas Indonesia, 2017. 